\title{
Characterization of Trichosporon species isolated from clinical specimens in Kuwait
}

\section{Correspondence \\ Zia U. Khan \\ ziauddin@hsc.edu.kw}

Received 4 December 2004

Accepted 16 March 2005

\author{
Suhail Ahmad, Manal Al-Mahmeed and Zia U. Khan \\ Department of Microbiology, Faculty of Medicine, Kuwait University, PO Box 24923, Safat 13110, \\ Kuwait
}

\begin{abstract}
Invasive trichosporonosis is an emerging infection of severely immunocompromised patients. It is principally caused by Trichosporon asahii, although some other species of the genus have also been implicated in the aetiology. In this work, 29 clinical isolates of Trichosporon species recovered from 29 different patients over a 6 -year period were studied for phenotypic and genotypic characteristics. Two morphotypes were recognized on the basis of colony characteristics. The colonies of 25 isolates appeared flat and centrally wrinkled, while the other four isolates appeared dry and irregularly folded or verrucosed. Based on substrate assimilation profiles, all 29 isolates were identified as $T$. asahii using the Vitek 2 system. However, PCR amplification of rRNA gene sequences identified only 25 of the 29 isolates as $T$. asahii. The identity of the remaining four isolates was established as Trichosporon asteroides by direct DNA sequencing of the internally transcribed spacer (ITS)-1 and ITS-2 regions in the rRNA gene fragment amplified by PCR using panfungal primers. Fingerprinting carried out by randomly amplified polymorphic DNA analysis showed genotypic heterogeneity among the $25 T$. asahii and four $T$. asteroides isolates. These data suggest that $T$. asahii is the major species associated with clinical specimens in Kuwait.
\end{abstract}

\section{INTRODUCTION}

The genus Trichosporon Behrend includes anamorphic yeasts with distinct morphological characteristics of budding yeast cells and true mycelia that disarticulate to form arthroconidia. In 1992, Gueho et al. (1992) revised the genus Trichosporon using the characteristics of morphology, ultrastructure, physiology, the ubiquinone system, DNA G+C content, DNA-DNA reassociation and 26S rRNA gene partial sequences. Based on a study of 101 strains isolated from diverse sources, 19 taxa were distinguished. Within the taxa isolated from humans, a distinction was made between those isolated from systemic infections and those that caused pubic or non-pubic white piedra. In a subsequent study, Sugita et al. (1995) investigated ten clinical isolates of Trichosporon cutaneum originating from deep-seated and mucosa-associated infections by use of a DNA-DNA reassociation technique and identified nine of the isolates as Trichosporon asahii and one as Trichosporon ovoides. These findings suggested that $T$. cutaneum is a heterogeneous species and that the causative agents of trichosporonosis exist in four or more species. Since the publication of major monographs on yeast taxonomy, each containing 19 Tri-

Abbreviations: ITS, internally transcribed spacer; RAPD, random amplification of polymorphic DNA.

The GenBank/EMBL/DDBJ accession numbers for genes from Trichosporon asahii strains are AJ864866 and AJ864867, and for Trichosporon asteroides strains are AJ864868-AJ864871. chosporon species, 15 additional species have been described (Fell \& Scorzetti, 2004; Middelhoven et al., 2004). These new species have been identified on the basis of DNA sequence analysis of the internally transcribed spacer (ITS) regions and/or the D1/D2 region of the large subunit (26S) rRNA gene. In addition, assimilation of some new substrates, not traditionally used in yeast taxonomy, was also employed for delineating some of these species (Middelhoven et al., 2004). The genus Trichosporon now comprises 34 species/varieties (Fell \& Scorzetti, 2004; Middelhoven et al., 2004), seven of which, namely T. asahii, Trichosporon mucoides, Trichosporon asteroides, T. cutaneum, Trichosporon inkin, T. ovoides and Trichosporon loubieri, are known human pathogens causing disseminated or superficial infections (de Hoog et al., 2000; Middelhoven, 2003; Marty et al., 2003; Padhye et al., 2003). Additionally, T. asahii, T. mucoides, T. ovoides, Trichosporon montevideense and Trichosporon domesticum have also been implicated in summer-type hypersensitivity pneumonitis (Gueho et al., 1994; Nishiura et al., 1997; Sugita et al., 1998a).

There has been no study on phenotypic and genotypic characterization of Trichosporon species from the Middle East. In this communication, we report, for the first time, results of morphological, biochemical and molecular identification of 29 consecutive isolates of Trichosporon species obtained over a 6-year period from 29 different patients in Kuwait. 


\section{METHODS}

Reference strains. The reference strains of Trichosporon species used in this study were obtained from the Centraalbureau voor Schimmelcultures (CBS), Utrecht, The Netherlands. The following strains were used: T. asahii var. asahii CBS 2479, T. asahii var. asahii CBS 2530, T. asahii var. faecale CBS 4828, T. asteroides CBS 2481, T. inkin CBS 5585, T. mucoides CBS 7625 and Trichosporon jirovecii CBS 6864. The strains were grown on Sabouraud dextrose agar (SDA) (Difco Laboratories). Other reference strains used in this study included Candida albicans (ATCC 76615), Candida dubliniensis (type strain CD 36), Candida glabrata (ATCC 15545), Candida parapsilosis (ATCC 10233), Candida tropicalis (ATCC 750), Aspergillus fumigatus (CBS 113.26), Aspergillus terreus (CBS 118.27), Aspergillus flavus (CBS 113.32), Fusarium solani (ATCC 36031), Fusarium oxysporum (CBS 109898), Cryptococcus neoformans (ATCC 90112), Mycobacterium tuberculosis $\mathrm{H}_{37} \mathrm{Rv}$ and Escherichia coli BL21.

Isolation and identification of Trichosporon species. A total of 4007 clinical specimens were processed over a 6-year period (19972002) for the isolation of pathogenic fungi according to standard procedures (McGinnis, 1994) (Table 1). The clinical specimens were cultured on SDA supplemented with chloramphenicol $\left(50 \mathrm{mg} \mathrm{l}^{-1}\right)$. Blood specimens were cultured either by BACTEC 9240 (Becton Dickinson) or the Isostat lysis centrifugation system (Wampole Laboratories). Culture plates were incubated at $28{ }^{\circ} \mathrm{C}$ and observed daily for growth for up to 1 week. Colonies appearing as yeast-like in consistency were examined as a wet mount for microscopic characteristics. A total of 29 isolates showing budding yeast cells, hyphae and arthroconidia were provisionally identified as Trichosporon species (Table 1).

Study of morphologic characteristics and biochemical profile. The reference strains and clinical isolates were studied for colonial and microscopic characteristics on SDA and malt extract agar (MEA), respectively. Apart from rate of growth, the study of colony characteristics included texture, topography and colour. A small inoculum from an isolated colony of reference strains and test isolates was inoculated in the centre of the SDA plate. The plates were incubated at $28{ }^{\circ} \mathrm{C}$ and examined for growth for up to 10 days. Microscopic morphology was studied by the Dalmau technique (McGinnis, 1994). The slides were incubated in a moist chamber for $24-48 \mathrm{~h}$ and examined under highpower magnification for the formation of hyphae, budding yeast cells, arthroconidia, appresoria and sarcinae.

The reference strains of T. asahii, T. asteroides, T. inkin, T. mucoides and all the clinical isolates were studied for substrate assimilation profiles employing the Vitek 2 yeast identification system performed as recommended by the manufacturer. Each test isolate was freshly subcultured by streaking. The yeast suspension was automatically inoculated into a Vitek 2 ID-YST card and incubated at $35^{\circ} \mathrm{C}$. Readings

Table 1. Recovery of Trichosporon species isolates from clinical specimens in Kuwait during a 6-year period (1997-2002)

\begin{tabular}{|lcc|}
\hline $\begin{array}{l}\text { Year } \\
\text { of isolation }\end{array}$ & $\begin{array}{c}\text { No. of clinical } \\
\text { specimens processed }\end{array}$ & $\begin{array}{c}\text { No. of Trichosporon } \\
\text { species isolated }\end{array}$ \\
\hline 1997 & 257 & 1 \\
1998 & 735 & 6 \\
1999 & 420 & 2 \\
2000 & 598 & 7 \\
2001 & 880 & 6 \\
2002 & 1117 & 7 \\
\hline
\end{tabular}

were taken after $24 \mathrm{~h}$ incubation. The Vitek 2 ID-YST card has a database for 46 substrates and is programmed to identify only three Trichosporon species, namely T. asahii, T. inkin and T. mucoides.

PCR-based detection of Trichosporon species DNA. Genomic DNA from the reference and clinical Trichosporon species, as well as from other fungal and bacterial organisms, was isolated as described previously (Sugita et al., 1995; Ahmad et al., 2002). DNA samples were stored at $-20{ }^{\circ} \mathrm{C}$ until use. To design primers that would specifically amplify $T$. asahii or T. mucoides DNA, the sequences of the ITS region (including the ITS- 1 region, the $5 \cdot 8 \mathrm{~S}$ rRNA gene and the ITS-2 region), as well as the DNA sequences at the $3^{\prime}$ end of the $18 \mathrm{~S}$ and the $5^{\prime}$ end of the $26 \mathrm{~S}$ rRNA genes from several Trichosporon species, were aligned using CLUSTAL W (http://www.ebi.ac.uk/clustalw). Based on this alignment, two primer pairs (TASF+TASR and TMF+TMR) were designed for the detection of T. asahii and T. mucoides DNA, respectively, by PCR. The sequences of these primers were: TASF, 5'-GGATCATTAGTGATTGC CTTTATA-3'; TASR, 5' -AGCACGCTTCAACACAATGGAC-3'; TMF, 5'-GGATCATTAGTGAATTGCTCTTTGA-3'; and TMR, 5' -TTAGAA GCGCACTTCTCAAGTCT- $3^{\prime}$. The species specificity of the primers was confirmed by performing a BLAST search (Altschul et al., 1990). The TASF primer is specific for T. asahii and has been described previously (Sugita et al., 1998b, c), while the sequence of our TASR primer matched the sequence from five Trichosporon species, namely T. asahii, T. asteroides, Trichosporon japonicum, T. ovoides and Trichosporon aquatile. Furthermore, the DNA sequences of the TMF and TMR primers were found to be specific for four Trichosporon species, namely T. mucoides, T. jirovecii, T. cutaneum and Trichosporon dermatis. The clinical isolates that did not yield an amplified product by PCR with T. asahii-specific or T. mucoides primers were tested with the panfungal primers ITS1, ITS2, ITS3 and ITS4 (Ahmad et al., 2002; Fujita et al., 1995). The location of the TASF/TMF primers in the ITS- 1 region and the TASR/TMR primers in the ITS-2 region, as well as the primer-binding locations of the panfungal primers ITS1, ITS2, ITS3 and ITS4 used for PCR amplification of rRNA gene fragments, are shown in Fig. 1. PCR amplification with $T$. asahii-specific, T. mucoides or panfungal primers was performed with genomic DNA prepared from reference or clinical isolates of Trichosporon species and the amplified products were resolved by agarose gel electrophoresis as described previously (Ahmad et al., 2002).

DNA sequencing. To confirm the results obtained with assimilation patterns using the Vitek 2 system and PCR amplification of genomic DNA using T. asahii-specific primers, direct DNA sequencing of the ITS- 1 and ITS-2 regions in the PCR-amplified products was performed on two clinical isolates identified as T. asahii. DNA sequencing was also performed for clinical isolates that were identified as T. asahii based on assimilation patterns by Vitek 2 but that did not yield an amplified product with TASF/TASR or TMF/TMR primer combinations in PCR. For this purpose, the amplified DNA obtained with the ITS1 and ITS4 primers was subjected to sequencing and both strands were sequenced

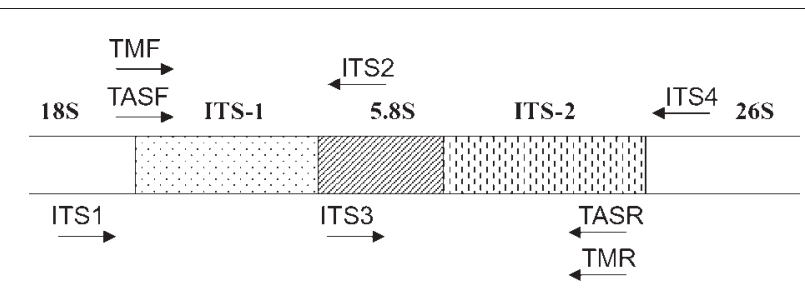

Fig. 1. The 18S rRNA gene, the ITS region (including ITS-1, the 5.8S rRNA gene and ITS-2) and the 26S rRNA gene showing the location of the T. asahii-specific primers (TASF and TASR), T. mucoides/ jirovecii primers (TMF and TMR) and the panfungal primers ITS1, ITS2, ITS3 and ITS4 used for PCR amplification. 
(Ahmad et al., 2004). DNA sequencing data were analysed using BLAST (Altschul et al., 1990).

Fingerprinting of Trichosporon species isolates by random amplification of polymorphic DNA (RAPD) analysis. Two short oligonucleotides were selected as single primers for fingerprinting of the 29 clinical Trichosporon species isolates by RAPD. The DNA sequences of these primers were GAC-1 (5'-GACGACGACGAC-3') and M13 (5'GAGGGTGGCGGTTCT-3') (Sugita et al., 2001a). The two RAPD assays were individually optimized (Ahmad et al., 2003; Sugita et al., 2001a). Amplifications in a total volume of $50 \mu \mathrm{l}$ contained $5 \mu \mathrm{l} 10 \times$ PCR buffer II (Perkin Elmer), $5 \mu \mathrm{l} 25 \mathrm{mM} \mathrm{MgCl}_{2}, 200 \mu \mathrm{M}$ dNTPs, 10 pmol GAC-1 or M13 primer, 2 U AmpliTaq DNA polymerase (Perkin Elmer) and $2 \mu \mathrm{l}$ genomic DNA. For primer GAC-1, an initial denaturation at $95^{\circ} \mathrm{C}$ for $3 \mathrm{~min}$ was followed by 40 cycles of $1 \mathrm{~min}$ at $95^{\circ} \mathrm{C}, 30 \mathrm{~s}$ at $45^{\circ} \mathrm{C}$ and $2.5 \mathrm{~min}$ at $72{ }^{\circ} \mathrm{C}$, and one cycle of $10 \mathrm{~min}$ at $72^{\circ} \mathrm{C}$. For primer $\mathrm{M} 13$, the cycling parameters included an initial denaturation at $95^{\circ} \mathrm{C}$ for $3 \mathrm{~min}, 40$ cycles of $1 \mathrm{~min}$ at $95^{\circ} \mathrm{C}, 30 \mathrm{~s}$ at $40{ }^{\circ} \mathrm{C}$ and $2.5 \mathrm{~min}$ at $72{ }^{\circ} \mathrm{C}$, followed by one cycle of $72{ }^{\circ} \mathrm{C}$ for $10 \mathrm{~min}$. Amplified products were separated by agarose gel electrophoresis and similarities and differences among DNA fragment banding patterns were visualized and recorded (Ahmad et al., 2003).

\section{RESULTS}

Of the 4007 clinical specimens processed during the study period (January 1997-December 2002), 29 isolates (K1K29) of Trichosporon species originating from 29 different patients were obtained (Table 1). Information pertaining to the source of isolation and the underlying diseases of the patients yielding these isolates is provided in Table 2. The study of colony characteristics of the 29 clinical isolates on SDA revealed two distinct morphotypes: 25 isolates yielded cream-coloured colonies (18-34 mm diameter), which appeared flat with a farinose covering (Fig. 2a), while the remaining four isolates yielded smaller (19-24 mm diameter), irregularly folded or verrucosed colonies (Fig. 2b). Similar features were exhibited by the reference strains of

Table 2. Phenotypic and molecular characteristics of Trichosporon species isolates recovered from clinical specimens in Kuwait

\begin{tabular}{|c|c|c|c|c|c|c|}
\hline \multirow{2}{*}{$\begin{array}{l}\text { Isolate } \\
\text { no. }\end{array}$} & \multirow{2}{*}{$\begin{array}{c}\text { Clinical } \\
\text { specimen }\end{array}$} & \multirow[t]{2}{*}{ Underlying disease } & \multirow{2}{*}{$\begin{array}{c}\text { Colony } \\
\text { characteristics }^{*}\end{array}$} & \multicolumn{3}{|c|}{ Species identification } \\
\hline & & & & Vitek 2 ID-YST & rRNA gene PCR & $\begin{array}{l}\text { rRNA gene } \\
\text { sequencing }\end{array}$ \\
\hline K1 & Urine & $\mathrm{NA}$ & Type 1 & T. asahii & T. asahii & ND \\
\hline K2 & Urine & Kidney transplant & Type 1 & T. asahii & T. asahii & ND \\
\hline K3 & Urine & Cancer & Type 1 & T. asahii & T. asahii & $\mathrm{ND}$ \\
\hline K4 & Urine & Cancer & Type 1 & T. asahii & T. asahii & ND \\
\hline K5 & Urine & Cancer & Type 1 & T. asahii & T. asahii & ND \\
\hline K6 & Urine & Severe burns & Type 1 & T. asahii & T. asahii & ND \\
\hline K7 & Urine & Hemi-colectomy & Type 1 & T. asahii & T. asahii & ND \\
\hline K8 & Peritoneal fluid & Kidney failure & Type 1 & T. asahii & T. asahii & ND \\
\hline K9 & Sputum & RTA & Type 1 & T. asahii & T. asahii & ND \\
\hline K10 & Urine & NA & Type 1 & T. asahii & T. asahii & ND \\
\hline K11 & Urine & NA & Type 1 & T. asahii & T. asahii & ND \\
\hline K12 & Soft tissue & NA & Type 1 & T. asahii & T. asahii & ND \\
\hline K13 & Urine & NA & Type 1 & T. asahii & T. asahii & ND \\
\hline K14 & Urine & Low birth weight & Type 1 & T. asahii & T. asahii & ND \\
\hline K15 & Catheter site & AML & Type 1 & T. asahii & T. asahii & ND \\
\hline K16 & Sputum & Chest infection & Type 1 & T. asahii & T. asahii & ND \\
\hline K17 & Urine & NA & Type 1 & T. asahii & T. asahii & $\mathrm{ND}$ \\
\hline K18 & Urine & $\mathrm{NA}$ & Type 1 & T. asahii & T. asahii & T. asahii \\
\hline K19 & Urine & Cancer & Type 1 & T. asahii & T. asahii & T. asahii \\
\hline K20 & Blood & Cancer & Type 2 & T. asahii & Unidentified & T. asteroides \\
\hline K21 & Blood & Kidney failure & Type 2 & T. asahii & Unidentified & T. asteroides \\
\hline K22 & Blood & Cirrhosis & Type 1 & T. asahii & T. asahii & $\mathrm{ND}$ \\
\hline K23 & Catheter tip & Low birth weight & Type 2 & T. asahii & Unidentified & T. asteroides \\
\hline K24 & Urine & $\mathrm{NA}$ & Type 1 & T. asahii & T. asahii & $\mathrm{ND}$ \\
\hline K25 & Urine & NA & Type 1 & T. asahii & T. asahii & ND \\
\hline K26 & Urine & NA & Type 1 & T. asahii & T. asahii & ND \\
\hline K27 & Urine & NA & Type 1 & T. asahii & T. asahii & ND \\
\hline K28 & Urine & Kidney failure & Type 1 & T. asahii & T. asahii & $\mathrm{ND}$ \\
\hline K29 & Blood & Pleural effusion & Type 2 & T. asahii & Unidentified & T. asteroides \\
\hline
\end{tabular}

AML, acute myelocytic leukaemia; NA, not available; ND, not done; RTA, road traffic accident.

*Type 1 colonies initially appeared flat and centrally wrinkled with a farinose covering; type 2 colonies were dry and irregularly folded or verrucosed. 
(a)

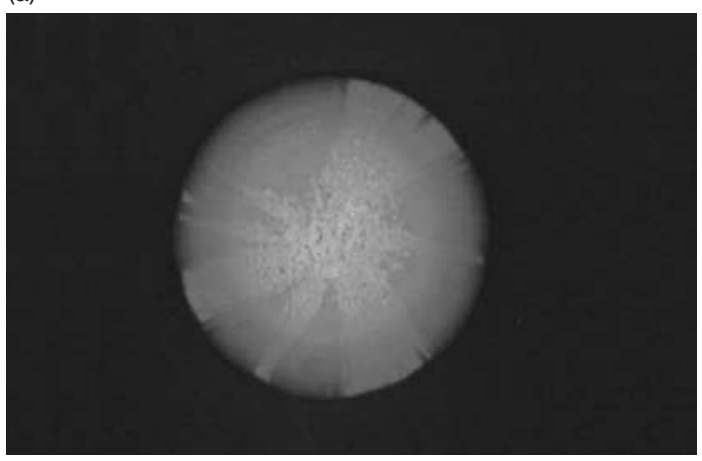

(b)

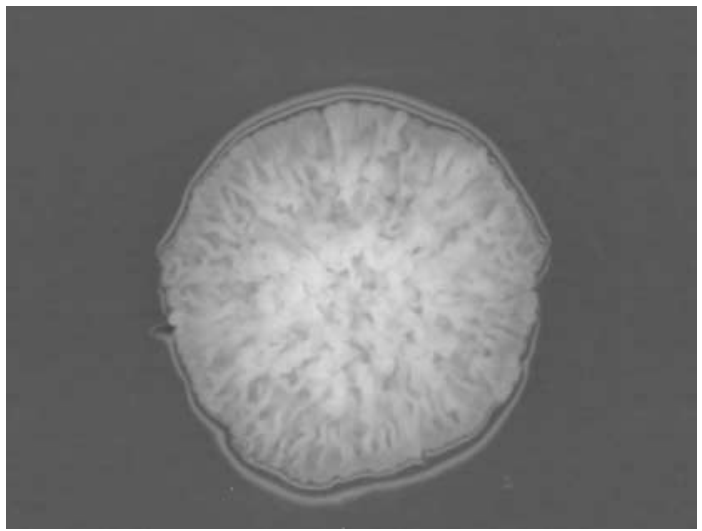

Fig. 2. Flat, centrally wrinkled colony of a clinical isolate of $T$. asahii (strain K17) (a) and folded (verrucosed) colony of T. asteroides, strain $\mathrm{K} 20$ (b) on SDA after 10 days at $28^{\circ} \mathrm{C}$.

T. asahii (CBS 2479) and T. asteroides (CBS 2481). Three of the clinical T. asteroides isolates also showed cracking of the agar. No discernible differences were observed in microscopic morphology. The assimilation profiles of the reference strains of T. asahii (CBS 2479, CBS 2530 and CBS 4828) and T. asteroides (CBS 2481) by the Vitek 2 system were not discriminatory. When the clinical isolates from Kuwait were subjected to identification by Vitek 2 ID-YST cards, all 29 isolates were identified as T. asahii. Of the 46 substrates included in the Vitek 2 ID-YST cards, 18 were assimilated by all the clinical isolates and eight were not, while 20 yielded variable results (data not shown), indicating the inability of the Vitek 2 identification system to discriminate among various Trichosporon species.

PCR performed with T. asahii-specific TASF and TASR primers yielded specific amplification of a DNA fragment ( $\sim 430$ bp) with genomic DNA from the reference cultures of two strains of T. asahii var. asahii (Fig. 3a, lanes 1 and 2) and from T. asahii var. faecalis (lane 3 ), but not from T. asteroides (lane 4), T. inkin (lane 5), T. mucoides (lane 6) or T. jirovecii (data not shown). Furthermore, PCR performed with T. mucoides primers (TMF and TMR) yielded specific amplification of a DNA fragment $(\sim 416 \mathrm{bp})$ with genomic DNA from reference cultures of $T$. mucoides (Fig. 3b, lane 5) and T. jirovecii (lane 6), but not from T. asahii var. asahii, T.
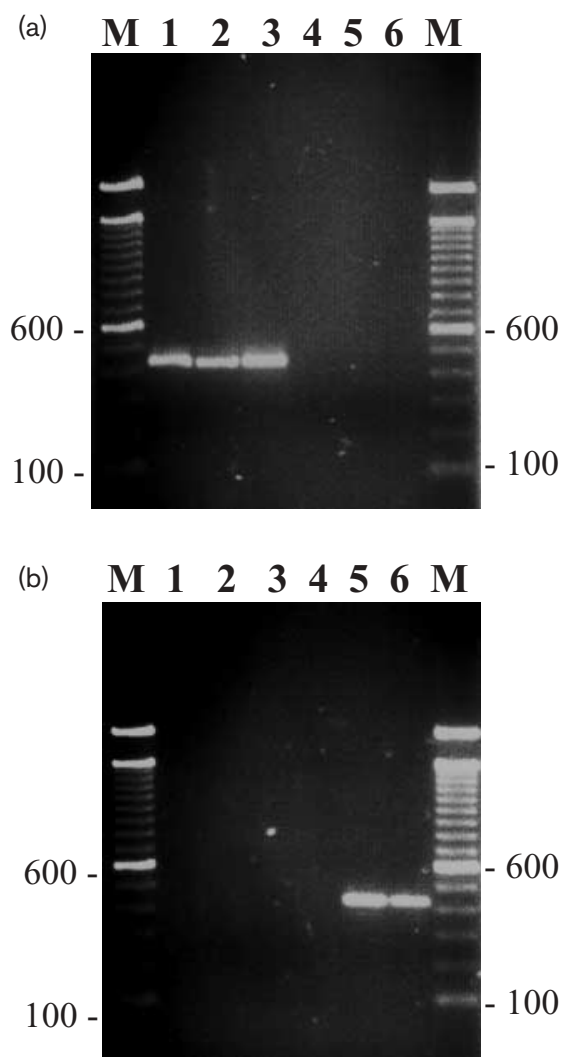

Fig. 3. Agarose gels of PCR products amplified from genomic DNA using the TASF and TASR primers (a) from T. asahii strains CBS 2479, CBS 2530 and CBS 4828 (lanes 1-3, respectively), T. asteroides (lane 4), T. inkin (lane 5) and T. mucoides (lane 6), and using the TMF and TMR primers (b) from T. asahii strains CBS 2479 and CBS 4828 (lanes 1 and 2, respectively), T. asteroides (lane 3), T. inkin (lane 4), T. mucoides (lane 5) and T. jirovecii (lane 6). Lane M, 100 bp DNA marker, with the positions of 100 and 600 bp fragments indicated.

asahii var. faecalis, T. asteroides and T. inkin (lanes 1-4, respectively). No amplification of a DNA fragment of any size was obtained when PCR was performed with T. asahiispecific or T. mucoides primers with genomic DNA isolated from reference cultures of Candida albicans, Candida $d u$ bliniensis, Candida glabrata, Candida parapsilosis, Candida tropicalis, A. fumigatus, A. terreus, A. flavus, F. solani, F. oxysporum, Cryptococcus neoformans, $M$. tuberculosis or E. coli (data not shown).

PCR amplification of genomic DNA with T. asahii-specific primers resulted in specific amplification of a single DNA fragment ( $\sim 430 \mathrm{bp}$ ) from 25 clinical Trichosporon isolates only (Fig. 4, lanes K1-K19, K22, K24-K28), while the remaining four isolates did not yield an amplified product. None of the 29 isolates yielded an amplified product when PCR amplification was performed with the TMF and TMR primers (data not shown). The DNA sequence of the ITS-1 and ITS-2 regions contained in the amplified fragment obtained with primers TASF and TASR from two randomly selected isolates (isolates K18 and K19) matched completely 


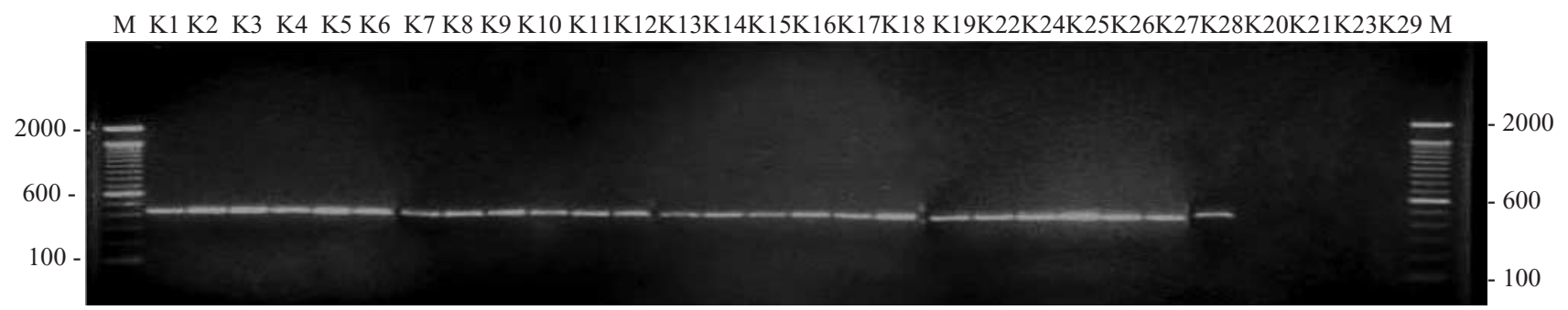

Fig. 4. Agarose gel of PCR products amplified from genomic DNA with the TASF and TASR primers obtained from the 29 clinical Trichosporon species isolates. The lane markings correspond to the isolate numbers (see Table 2). Lane M, 100 bp DNA marker, with the positions of 100, 600 and 2000 bp fragments indicated.

(100\%) with the reported sequences of some of the reference strains (CBS 2530, CBS 2479, CBS 7137, CBS 8520 and CBS 8640 ) of $T$. asahii only and not with other Trichosporon species or with other fungi (Table 3 , see below). The speciesspecific identity of the four unidentified isolates was investigated further.

PCR amplification of the ITS regions with the panfungal primers ITS1 and ITS2, ITS3 and ITS4, or ITS1 and ITS4, as well as with the ITS1 and TASR primers, resulted in specific amplification of a single DNA fragment from all four Trichosporon isolates, while no amplification was obtained with the TASF and ITS4 primer pair (data not shown). The DNA sequence of the ITS-1 region from all four isolates matched completely (100\%) with the DNA sequence of this region from T. asteroides strains CBS 7623 and M 9817 but differed at one nucleotide position from $T$. asteroides strain
CBS 2481 (Table 3). Furthermore, the sequence of the ITS-2 region matched completely (100\%) with the DNA sequence of this region from $T$. asteroides strains CBS 2481, CBS 7623 and M 9817, as well as from two T. asahii strains (Table 3).

Fingerprinting of 25 isolates confirmed as T. asahii using the GAC-1 RAPD primer yielded eight different patterns, which were arbitrarily referred to as patterns A-H (Fig. 5a). Only isolate $\mathrm{K} 1$ and $\mathrm{K} 5$ yielded the unique $\mathrm{A}$ and $\mathrm{H}$ patterns, respectively. Three (K2, K3 and K4), two (K7 and K25), six (K9, K13, K14, K15, K16 and K22), four (K6, K26, K27 and $\mathrm{K} 28)$, three (K8, K19 and K24) and five (K10, K11, K12, K17 and $\mathrm{K} 18$ ) isolates exhibited the B, C, D, E, F and G patterns, respectively. All four $T$. asteroides isolates exhibited a single pattern using the GAC-1 RAPD primer, which was distinct from the patterns exhibited by the T. asahii isolates (Fig. 5a,

Table 3. Specific nucleotides present at various positions in the ITS-1 and ITS-2 regions among reference strains of $T$. asahii and $T$. asteroides and clinical isolates from Kuwait

\begin{tabular}{|c|c|c|c|c|c|c|}
\hline \multirow{2}{*}{$\begin{array}{l}\text { Trichosporon } \\
\text { species }\end{array}$} & \multirow[t]{2}{*}{ Isolate no. } & \multirow{2}{*}{$\begin{array}{c}\text { GenBank } \\
\text { accession no. }\end{array}$} & \multicolumn{3}{|c|}{ Nucleotide in ITS-1 at: } & \multirow{2}{*}{$\begin{array}{l}\text { Nucleotide in } \\
\text { ITS-2 at: } \\
\text { Position } 53\end{array}$} \\
\hline & & & Position 12 & Position 15 & Position 56 & \\
\hline \multirow[t]{11}{*}{ T. asahii } & CBS 2479 & AB018013 & $\mathrm{T}$ & A & $\mathrm{C}$ & $\mathrm{T}$ \\
\hline & CBS 2482 & AF444434 & $\mathrm{T}$ & A & $\mathrm{T}$ & $\mathrm{C}$ \\
\hline & CBS 2530 & AB018014 & $\mathrm{T}$ & A & $\mathrm{C}$ & $\mathrm{T}$ \\
\hline & CBS 4828 & AF444419 & $\mathrm{T}$ & $\mathrm{A}$ & $\mathrm{C}$ & $\mathrm{C}$ \\
\hline & CBS 7137 & AF444466 & $\mathrm{T}$ & $\mathrm{A}$ & $\mathrm{C}$ & $\mathrm{T}$ \\
\hline & CBS 8520 & AF444457 & $\mathrm{T}$ & A & $\mathrm{C}$ & $\mathrm{T}$ \\
\hline & CBS 8640 & AF444465 & $\mathrm{T}$ & A & $\mathrm{C}$ & $\mathrm{T}$ \\
\hline & ST8H-6a & AY359870 & $\mathrm{T}$ & A & $\mathrm{C}$ & $\mathrm{T}$ \\
\hline & wb466 & AF455425 & $\mathrm{T}$ & A & $\mathrm{C}$ & $\mathrm{T}$ \\
\hline & K18 & AJ864866 & $\mathrm{T}$ & A & $\mathrm{C}$ & $\mathrm{T}$ \\
\hline & K19 & AJ864867 & $\mathrm{T}$ & A & $\mathrm{C}$ & $\mathrm{T}$ \\
\hline \multirow[t]{7}{*}{ T. asteroides } & CBS 2481 & AF444416 & A & $\mathrm{T}$ & $\mathrm{T}$ & $\mathrm{C}$ \\
\hline & CBS 7623 & AB018018 & A & $\mathrm{T}$ & $\mathrm{C}$ & $\mathrm{C}$ \\
\hline & M 9817 & $\mathrm{AB} 031521$ & A & $\mathrm{T}$ & $\mathrm{C}$ & $\mathrm{C}$ \\
\hline & K20 & AJ864868 & A & $\mathrm{T}$ & $\mathrm{C}$ & $\mathrm{C}$ \\
\hline & $\mathrm{K} 21$ & AJ864869 & A & $\mathrm{T}$ & $\mathrm{C}$ & $\mathrm{C}$ \\
\hline & K23 & AJ864870 & A & $\mathrm{T}$ & $\mathrm{C}$ & $\mathrm{C}$ \\
\hline & K29 & AJ864871 & A & $\mathrm{T}$ & $\mathrm{C}$ & $\mathrm{C}$ \\
\hline
\end{tabular}




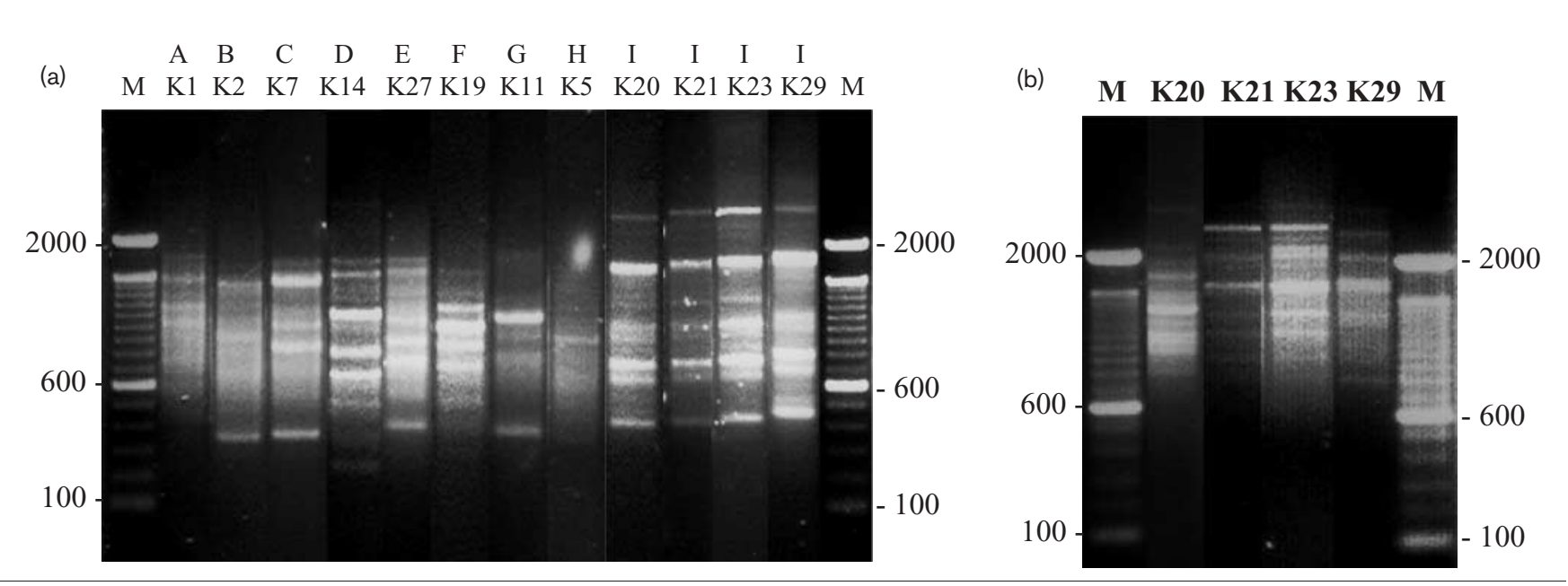

Fig. 5. Representative agarose gels of fingerprinting patterns from RAPD analyses of genomic DNA with the GAC-1 primer from selected T. asahii isolates and all four T. asteroides isolates (a) and with the M13 primer from the four T. asteroides isolates (b). The lane markings correspond to the isolate numbers (see Table 2). Lane M, 100 bp DNA marker, with the positions of 100,600 and 2000 bp fragments indicated.

pattern I). However, RAPD analysis performed with the M13 primer exhibited heterogeneity among the four T. asteroides isolates (Fig. 5b).

\section{DISCUSSION}

The taxonomy of Trichosporon is evolving fast (Fell \& Scorzetti, 2004; Middelhoven et al., 2004). Several new taxa have recently been proposed for inclusion in the genus (Fell \& Scorzetti, 2004; Middelhoven et al., 1999, 2000, 2001; Sugita \& Nakase, 1998; Sugita et al., 2002b). Trichosporon species are emerging opportunistic pathogens of immunocompromised patients, particularly those with granulocytopenia (Fleming et al., 2002; Walsh et al., 2004). The number of Trichosporon species causing disseminated disease is expanding; T. asteroides and $T$. loubieri have recently been shown to cause disseminated trichosporonosis (Kustimur et al., 2002; Marty et al., 2003; Padhye et al., 2003). Disseminated trichosporonosis is associated with high mortality, despite antifungal therapy. Since Trichosporon species may have different antifungal susceptibilities (McGinnis et al., 1998; Paphitou et al., 2002), it is important to identify them accurately for specific therapy. Identification based solely on carbon and nitrogen assimilation profiles may not be totally reliable (Middelhoven et al., 2004).

In this study, we have presented data on the phenotypic and molecular identification of Trichosporon species recovered from various clinical specimens in Kuwait. Although Trichosporon isolates were collected over a 6-year period from 29 different patients, only two colony types were recognized, which corresponded to T. asahii and T. asteroides. This lack of species diversity in our isolates may be attributed to the types of specimen cultured. Most of our isolates originated from urine and blood specimens (79\%) and none from superficial sites such as skin or hair, which may have a different species spectrum (Lee et al., 1990). It is interesting that three of the four isolates exhibiting a different colony type originated from blood and were later identified as T. asteroides. They also showed cracking of the agar after 7 days of incubation at $28{ }^{\circ} \mathrm{C}$, a phenomenon seen mostly among T. inkin isolates (Gueho et al., 1994); this has not been described for isolates of T. asteroides.

Although all of our isolates were identified by the Vitek 2 system as $T$. asahii, their assimilation profiles were not identical. Utilization of D-galactose, D-gluconate, isoleucine arylamidase and $\beta$-xylosidase and non-utilization of $\mathrm{D}$ melezitose, D-sorbitol, D-mannitol, L-rhamnose and citrate was shown by the $T$. asteroides isolates, and some of these profiles were also exhibited by a few $T$. asahii isolates. In this context, it should be mentioned that, while phenotypic characteristics including assimilation of a large number of carbon and nitrogen compounds form the basis for species identification of yeasts, the inconsistency of assimilation results has been a problem. The Vitek 2 system is programmed to identify only three species of Trichosporon, namely, T. asahii, T. inkin and T. mucoides. Consequently, strains may be misidentified, and genetically distinct species could be overlooked. The application of modern molecular methods including sequencing of rRNA genes offers a reliable alternative to overcome this difficulty (Fell \& Scorzetti, 2004; Middelhoven et al., 2004).

Previous studies have shown that $T$. asahii can rapidly be identified by PCR using T. asahii-specific primers (Sugita et al., 1998b, c, 2001b). These studies have targeted either the divergent region of the $26 \mathrm{~S}$ rRNA gene or the more variable ITS region, located between the $18 \mathrm{~S}$ and $26 \mathrm{~S}$ rRNA genes and comprising ITS-1 (between the $18 \mathrm{~S}$ and 5.8S rRNA genes) and ITS-2 (between the 5.8S and 26S rRNA genes) (Fig. 1). Other targets that show species-specific variations among Trichosporon species have not been explored, mainly due to the limited number of molecular studies carried out. We have 
also established, in this study, a PCR assay for specific detection of DNA from T. asahii and T. mucoides. Although the T. asahii-specific forward primer (TASF) has been used previously, the reverse primers used in earlier studies were either panfungal or homologous to sequences from several Trichosporon species (Sugita et al., 1998b, c, 2001b). However, the primers for the detection of T. mucoides DNA have not been described previously.

The amplification of DNA from 25 of 29 clinical isolates from Kuwait with T. asahii-specific primers suggested that only 25 isolates were actually T. asahii strains, while the remaining four isolates remained unidentified. The ITS- 1 and ITS-2 regions are highly conserved among Trichosporon species and sequencing of these two regions is sufficient to establish the identity of Trichosporon or other fungal organisms (Sugita et al., 1999, 2002a). DNA sequencing of the ITS-1 and ITS-2 regions from two of the 25 isolates confirmed the speciesspecific identity of these isolates. Direct DNA sequencing of the ITS- 1 and ITS- 2 regions obtained with panfungal primers also confirmed the identity of the four discrepant isolates as T. asteroides. The ITS- 1 and ITS-2 regions from T. asahii and T. asteroides are highly conserved. The reported sequence of the ITS- 1 region from T. asahii differs from the T. asteroides sequence in two or three nucleotide positions (one nucleotide is the same in some reference strains of T. asahii and T. asteroides), while the sequence of the ITS- 2 region is either identical or varied at a single nucleotide position from these two Trichosporon species (Sugita et al., 1999, 2002a) (Table $3)$. The TASF primer is T. asahii-specific as the two nucleotides at the $3^{\prime}$ end are different in T. asteroides, while the sequence of TASR is identical in T. asahii and T. asteroides (Sugita et al., 1999). On the basis of the above observations, T. asahii and T. asteroides appear to be closely related species (Middelhoven et al., 2004).

The fingerprinting analyses using RAPD primers, shown previously to yield variable patterns for clinical $T$. asahii isolates (Sugita et al., 2001a), demonstrated genetic diversity among the Trichosporon isolates from Kuwait. Interestingly all four $T$. asteroides isolates clustered together and exhibited a unique pattern with the GAC-1 primer. However, some heterogeneity among these strains was revealed using the M13 primer. Only one previous study carried out in Japan has investigated genetic diversity among clinical and environmental isolates of Trichosporon species (Sugita et al., 2001a). The data obtained with three RAPD primers showed limited diversity among clinical Trichosporon species isolates, as the similarity of polymorphic bands was very high (91\%).

Considering the fact that Kuwait has a heterogeneous population representing different nationalities, it was anticipated that a wide spectrum of medically important species might occur in clinical specimens. However, this study reinforces the current view that $T$. asahii is the most common species associated with human clinical specimens and has a wide geographic distribution. Moreover, the currently available Vitek 2 yeast identification system is not adequately updated to identify correctly all the clinically relevant
Trichosporon species, and direct DNA sequencing of the rRNA gene ITS region is required to achieve definitive identification.

\section{ACKNOWLEDGEMENTS}

This study was supported by Research Administration grants YM02/02, MI 118 and the College of Graduate Studies, Kuwait University. We thank Zaiba Khan for technical assistance.

\section{REFERENCES}

Ahmad, S., Khan, Z., Mustafa, A. S. \& Khan, Z. U. (2002). Seminested PCR for diagnosis of candidemia: comparison with culture, antigen detection, and biochemical methods for species identification. J Clin Microbiol 40, 2483-2489.

Ahmad, S., Khan, Z., Mustafa, A. S. \& Khan, Z. U. (2003). Epidemiology of Candida colonization in an intensive care unit of a teaching hospital in Kuwait. Med Mycol 41, 487-493.

Ahmad, S., Khan, Z., Mokaddas, E. \& Khan, Z. U. (2004). Isolation and molecular identification of Candida dubliniensis from non-human immunodeficiency virus-infected patients in Kuwait. J Med Microbiol 53, 633-637.

Altschul, S. F., Gish, W., Miller, W., Myers, E. W. \& Lipmann, D. J. (1990). Basic local alignment search tool. J Mol Biol 215, 403-410.

de Hoog, G. S., Guarro, J., Gene, J. \& Figueras, M. J. (2000). Atlas of Clinical Fungi. Centraalbureau voor Schimmelcultures, Utrecht, The Netherlands, and Facultat de Medicina, Universitat Rovira i Virgili, Reus, Spain.

Fell, J. W. \& Scorzetti, G. (2004). Reassignment of the basidiomycetous yeasts Trichosporon pullulans to Guehomyces pullulans gen. nov., comb. nov. and Hyalodendron lignicola to Trichosporon lignicola comb. nov. Int J Syst Evol Microbiol 54, 995-998.

Fleming, R. V., Walsh, T. J. \& Anaissie, E. J. (2002). Emerging and less common fungal pathogens. Infect Dis Clin North Am 16, 915-933.

Fujita, S., Lasker, B. A., Lott, T. J., Reiss, E. \& Morrison, C. J. (1995). Microtitration plate enzyme immunoassay to detect PCR-amplified DNA from Candida species in blood. J Clin Microbiol 33, 962-967.

Gueho, E., Smith, M. T., de Hoog, G. S., Billon-Grand, G., Christen, R. \& Batenburg-van der Vegte, W. H. (1992). Contributions to a revision of the genus Trichosporon. Antonie van Leeuwenhoek 61, 289-316.

Gueho, E., Improvisi, L., de Hoog, G. \& Dupont, B. (1994). Trichosporon on humans: a practical account. Mycoses 37, 3-10.

Kustimur, S., Kalkanci, A., Caglar, K., Dizbay, M., Aktas, F. \& Sugita, T. (2002). Nosocomial fungemia due to Trichosporon asteroides: firstly described bloodstream infection. Diagn Microbiol Infect Dis 43, $167-170$.

Lee, J. W., Melcher, G. A., Rinaldi, M. G., Pizzo, P. A. \& Walsh, T. J. (1990). Patterns of morphologic variation among isolates of Trichosporon beigelii. J Clin Microbiol 28, 2823-2827.

Marty, F. M., Barouch, D. H., Coakley, E. P. \& Baden, L. R. (2003). Disseminated trichosporonosis caused by Trichosporon loubieri. J Clin Microbiol 41, 5317-5320.

McGinnis, M. R. (1994). Mycology. In Clinical Microbiology Procedures Handbook, Section 6, pp. 6.1.1-6.1.6.1.12. Edited by H. D. Isenberg. Washington, DC: American Society for Microbiology.

McGinnis, M. R., Pasarell, L., Sutton, D. A., Fothergill, A. W., Cooper, C. R., Jr \& Rinaldi, M. G. (1998). In vitro activity of voriconazole against selected fungi. Med Mycol 36, 239-242.

Middelhoven, W. J. (2003). Identification of clinically relevant Trichosporon species. Mycoses 46, 7-11. 
Middelhoven, W. J., Scorzetti, G. \& Fell, J. W. (1999). Trichosporon guehoae sp. nov., an anamorphic basidiomycetous yeast. Can J Microbiol $45,686-690$.

Middelhoven, W. J., Scorzetti, G. \& Fell, J. W. (2000). Trichosporon veenhuisii sp. nov., an alkane-assimilating anamorphic basidiomycetous yeast. Int J Syst Evol Microbiol 50, 381-387.

Middelhoven, W. J., Scorzetti, G. \& Fell, J. W. (2001). Trichosporon porosum comb. nov., an anamorphic basidiomycetous yeast inhabiting soil, related to the loubieri/laibachii group of species that assimilate hemicelluloses and phenolic compounds. FEMS Yeast Res 1, 15-22.

Middelhoven, W. J., Scorzetti, G. \& Fell, J. W. (2004). Systematics of the anamorphic basidiomycetous yeast genus Trichosporon Behrend with the description of five novel species: Trichosporon vadense, T. smithiae, T. dehoogii, T. scarabaeorum and T. gamsii. Int J Syst Evol Microbiol 54, 975-986.

Nishiura, Y., Nakagawa-Yoshida, K., Suga, M., Shinoda, T., Gueho, E. \& Ando, M. (1997). Assignment and serotyping of Trichosporon species: the causative agents of summer-type hypersensitivity pneumonitis. J Med Vet Mycol 35, 45-52.

Padhye, A. A., Verghese, S., Ravichandran, P., Balamurugan, G., Hall, L., Padmaja, P. \& Fernandez, M. C. (2003). Trichosporon loubieri infection in a patient with adult polycystic kidney disease. $J$ Clin Microbiol 41, 479-482.

Paphitou, N. I., Ostrosky-Zeichner, L., Paetznick, V. L., Rodriguez, J. R., Chen, E. \& Rex, J. H. (2002). In vitro antifungal susceptibilities of Trichosporon species. Antimicrob Agents Chemother 46, 1144-1146.

Sugita, T. \& Nakase, T. (1998). Trichosporon japonicum sp. nov. isolated from the air. Int J Syst Bacteriol 48, 1425-1429.

Sugita, T., Nishikawa, A., Shinoda, T. \& Kume, H. (1995). Taxonomic position of deep-seated, mucosa-associated, and superficial isolates of Trichosporon cutaneum from trichosporonosis patients. J Clin Microbiol 33, 1368-1370.

Sugita, T., Nishikawa, A., Ikeda, R., Shinoda, T., Sakashita, H., Sakai, Y.
\& Yoshizawa, Y. (1998a). First report of Trichosporon ovoides isolated from the home of a summer-type hypersensitivity pneumonitis patient. Microbiol Immunol 42, 475-478.

Sugita, T., Nishikawa, A. \& Shinoda, T. (1998b). Rapid detection of species of the opportunistic yeast Trichosporon by PCR. J Clin Microbiol 36, 1458-1460.

Sugita, T., Nishikawa, A. \& Shinoda, T. (1998c). Identification of Trichosporon asahii by PCR based on sequences of the internal transcribed spacer regions. J Clin Microbiol 36, 2742-2744.

Sugita, T., Nishikawa, A., Ikeda, R. \& Shinoda, T. (1999). Identification of medically relevant Trichosporon species based on sequences of internal transcribed spacer regions and construction of a database for Trichosporon identification. J Clin Microbiol 37, 1985-1993.

Sugita, T., Ichikawa, T., Matsukura, M., Sueda, M., Takashima, M., Ikeda, R., Nishikawa, A. \& Shinoda, T. (2001a). Genetic diversity and biochemical characteristics of Trichosporon asahii isolated from clinical specimens, houses of patients with summer-type-hypersensitivity pneumonitis, and environmental materials. J Clin Microbiol 39, $2405-2411$

Sugita, T., Nakajima, M., Ikeda, R., Niki, Y., Matsushima, T. \& Shinoda, T. (2001 b). A nested PCR assay to detect DNA in sera for the diagnosis of deep-seated trichosporonosis. Microbiol Immunol 45, 143-148.

Sugita, T., Nakajima, M., Ikeda, R., Matsushima, T. \& Shinoda, T. (2002a). Sequence analysis of the ribosomal DNA intergenic spacer 1 regions of Trichosporon species. J Clin Microbiol 40, 1826-1830.

Sugita, T., Takashima, M., Nakase, T., Ichikawa, T., Shinoda, T. \& Nishikawa, A. A. (2002b). A basidiomycetous anamorphic yeast, Trichosporon terricola sp. nov., isolated from soil. J Gen Appl Microbiol 48, 293-297.

Walsh, T. J., Groll, A., Hiemenz, J., Fleming, R., Roilides, E. \& Anaissie, E. (2004). Infections due to emerging and uncommon medically important fungal pathogens. Clin Microbiol Infect 10 (Suppl. 1), 48-66. 